\title{
The impact of Minimum Energy Efficiency Standards: some evidence from the London office market
}

Article

Accepted Version

Creative Commons: Attribution-Noncommercial-No Derivative Works 4.0

McAllister, P. and Nase, I. (2019) The impact of Minimum Energy Efficiency Standards: some evidence from the London office market. Energy Policy, 132. pp. 714-722. ISSN 0301 4215 doi: https://doi.org/10.1016/j.enpol.2019.05.060 Available at https://centaur.reading.ac.uk/84242/

It is advisable to refer to the publisher's version if you intend to cite from the work. See Guidance on citing.

To link to this article DOI: http://dx.doi.org/10.1016/j.enpol.2019.05.060

Publisher: Elsevier

All outputs in CentAUR are protected by Intellectual Property Rights law, including copyright law. Copyright and IPR is retained by the creators or other copyright holders. Terms and conditions for use of this material are defined in the End User Agreement.

www.reading.ac.uk/centaur

\section{CentAUR}


Central Archive at the University of Reading

Reading's research outputs online 
The Impact of Minimum Energy Efficiency Standards: Some Evidence from the London Office Market.

Pat McAllister, Department of Real Estate and Planning, University of Reading. Ilir Nase, Department of Management in the Built Environment, TU Delft 


\begin{abstract}
This paper provides a preliminary evaluation of staged introduction of the Minimum Energy Efficiency Standards in England and Wales in the period after announcement but before policy implementation. A process evaluation of the specific policy design focussing on potential sources of policy failure is provided. Drawing upon a database of all EPCs registered for offices in London, preliminary empirical evidence is presented on policy outcomes post-announcement and pre-implementation period. The extent to which EPC G and F rated office buildings in London have improved their EPC rating in anticipation of the introduction of the policy between 2011 until 2017 is analysed. It is found that a maximum of $0.65 \%$ of the properties affected by the introduction of minimum standards had modifications that could have been triggered by the policy intervention in the period prior to policy implementation.
\end{abstract}

Key words: Minimum energy efficiency standards. Commercial real estate. Policy evaluation. 


\section{Introduction}

In the UK, with the primary objective of reducing carbon emissions, improving the energy efficiency of the building stock has been subject to evolving policy mixes. Over the last two decades, an array of policy instruments have been announced, introduced, amended, withdrawn and/or continued. The policy instruments have included enhanced construction and design standards (e.g. building control regulation), compulsory energy labelling (Energy Performance Certificates and Display Energy Certificates) as well as a fairly unstable range of financial penalties and incentives (e.g. the Green Deal, Feed-in Tariffs, Energy Efficiency Opportunities Scheme, Climate Change Levy). Adding to the prevailing policy mix and pioneering the use of minimum energy performance standards (MEPS) for existing buildings, in 2011 the introduction of Minimum Energy Efficiency Standards (MEES) was announced. The Energy Act 2011 required that, from April 2018, landlords would not be able to let properties that did not meet a minimum energy performance standard - an Energy Performance Certificate rating of $\mathrm{E}$. The UK government's subsequent impact analysis estimated that approximately $10 \%$ of non-domestic buildings had an Energy Performance Certificates (EPC) rating of G, a further $8 \%$ had an F rating representing around 200,000 units of the leased commercial stock in England and Wales (Department of Energy and Climate Change, 2015).

This paper provides a preliminary policy evaluation of this 'command and control' policy instrument and presents some preliminary evidence of the effectiveness of the Minimum Energy Efficiency Standards in the period after announcement but before implementation of the regulation. The initial section of the paper discusses minimum energy performance standards (MEPS) as a policy instrument. This is followed by a process evaluation of the specific policy design in the English context focussing on potential sources of policy failure. Drawing upon a database of all EPCs for offices registered in London, preliminary empirical evidence is presented on policy outcomes in the period postannouncement and pre-implementation. The extent to which EPC G and F rated buildings have improved their EPC rating in the period from 2011 until 2017 is analysed. 


\section{Background and Context}

\subsection{MEES as a Policy Instrument}

Since the energy crisis of the 1970s, MEPS have been widely applied across numerous consumer and commercial products. Rather than mandating specific technologies or designs, MEPS mandate minimum energy efficiency performance for products but with a focus on actual or hypothetical performance in use and operation, MEPS do not typically address energy efficiency in production or decommissioning. In terms of policy design, a common criticism of this type of command-and-control regulation is that, by imposing identical standards on all market participants, they may force a proportion of market participants to implement economically inefficient measures (Stavins, 2003). A key issue is the extent to which the standards are technology-forcing (standards requiring a higher level of energy efficiency than currently available with established technologies). Used mainly to promote innovation, technology-forcing environmental regulation has been rare in the construction and real estate sectors.

Various forms of market failure have tended to steer government intervention towards command-and control rather than market based solutions to improving energy performance. Market failure is encompassed in an "energy efficiency gap" whereby market participants fail to invest in measures which are both economically and energy efficient. A range of technical, economic, behavioural and organisational barriers have been proposed to explain the energy efficiency gap - risk aversion, hidden costs, information and knowledge limitations, access to capital, split incentive problems, bounded rationality and status quo bias among others. Such a market failure rationale is explicit in the UK government's justification for the introduction of MEES.

"Various approaches have been tried in the past to improve the energy efficiency of the PRS ${ }^{1}$. These include voluntary approaches, information services, tax breaks for

\footnotetext{
${ }^{1}$ Private Rented Sector
} 
landlords, and subsidies for the installation of energy efficiency measures...These approaches have been unsuccessful in overcoming the market barriers..." (Department of Energy and Climate Change, 2015, 16).

The core critique of this type of product efficiency regulation is that it embodies a governmental assessment of appropriate minimum standards and, consequently, introduces the risk of government failure. Sachs (2012) outlines the fairly standard neo-liberal criticisms of command-and-control regulation. In essence, the argument is that the private sector is more effective than government at gathering, processing and acting upon information regarding the costs and benefits of energy efficiency improvements. Inflexible regulation is expected to be sub-optimal because government is perceived to be poor at fostering technological innovation, policy design is prone to bias through lobbying by special interest groups and command-and-control regulation tend to assume that a single policy fits all failing to account for the varying costs of policy compliance to market participants.

However, it is also acknowledged that MEPS have the potential to generate a bundle of positive policy outcomes. Minimum product standards avoid the informational problems that can plague markets. In contrast to certification approaches, the simplicity of MEPS means that market participants do not need to acquire a comprehensive knowledge about the trade-offs between capital investment in energy efficiency measures and long-term operational savings. The most direct economic and environmental benefits tend to be cost savings from decreased operating costs of energy-consuming equipment (with potential to redeploy savings gained from lower energy production and consumption) and reduced energy consumption leading to lower pollution and greenhouse gas emissions. For instance, the National Academy of Sciences (2009) estimated that applying reasonable energy efficiency measures for existing and new buildings could eliminate the requirement to build any additional power stations in the United States. In a detailed review of environmental policies affecting the real estate sector, Deloitte (2014) found that among institutional owners the proposed MEES were amongst the most positively perceived environmental policy instruments in the prevailing policy mix. In this qualitative 
survey research, market participants identified high levels of familiarity and effectiveness and low levels of administrative burden and costs as the main benefits.

A commonly cited key benefit of MEPS is that they effectively remove the most harmful products from the market. From the perspective of MEES, in broad terms the expected process of market transformation is illustrated in Figure 1. The anticipated policy outcome is that most properties rated G and $\mathrm{F}$ will be removed from the market following when a requirement to comply with MEES occurs. A proportion of the least energy efficient stock will remain in the market. Akin to the exemption of vintage cars from the Ministry of Transport test process, buildings recognised as being of historical significance will be exempt. Identifying the modifications to buildings produced by the policy instrument raises causality issues. Relatively straightforward cases are when an asset owner carries out the minimum necessary modifications to meet a minimum threshold. In such cases, the existence of the policy instrument is a necessary condition for the modifications to occur. In a proportion of cases, it may be rational to achieve a higher than minimum threshold because cost differences between matching the minimum standard and a higher than minimum standard are marginal. More difficult cases to attribute to policy instrument occur when the need to comply triggers a response by the owner that produces major modifications to or complete replacement of a building resulting in energy performance substantially above the minimum standard. A sufficient condition here is that major refurbishment or redevelopment is financially feasible. A large proportion of such buildings would have been redeveloped or refurbished in the absence of the policy instrument and the most likely policy effect is to bring forward modifications rather than cause them. 
Figure 1 Pre- and Post-MEPS Policy Scenarios

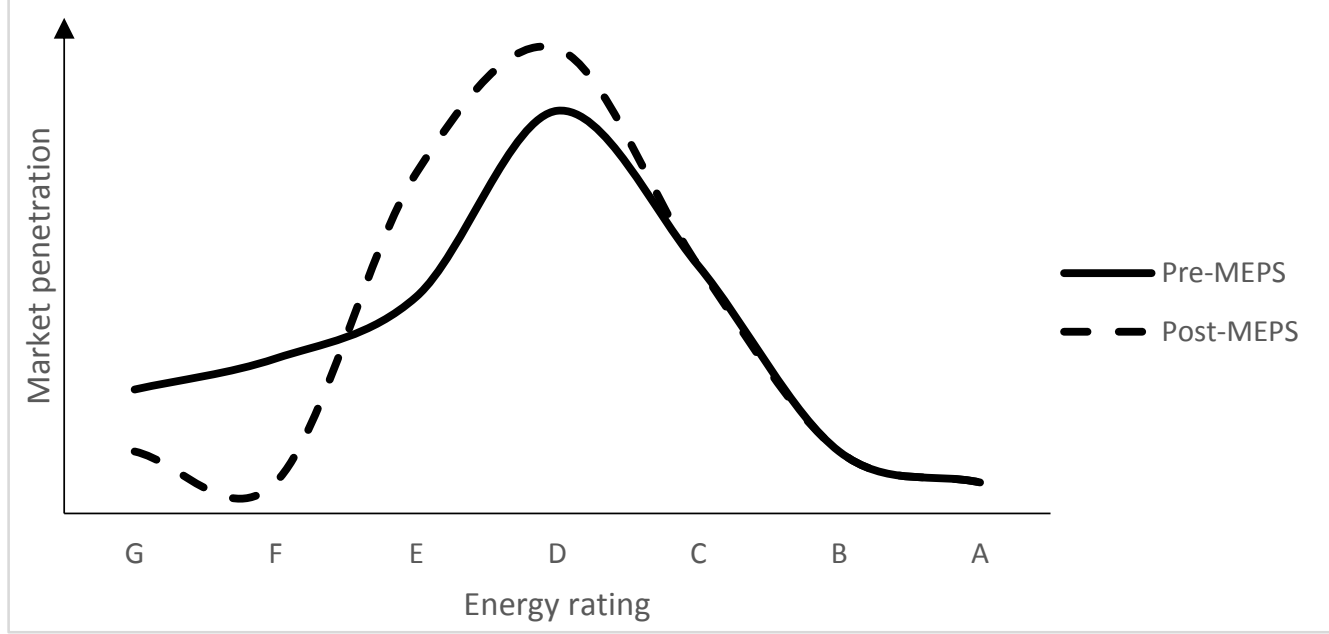

Nonetheless, there remain numerous major and minor potential sources of policy failure. Fairly fundamentally, there is concern that the EPC rating may be an inappropriate performance standard for the policy instrument. There is a body of empirical evidence illustrating an energy performance gap in both residential and commercial properties between energy ratings based on hypothetical performance and actual energy consumption in use (see Van den Brom, Meijer and Visscher, 2018 for a discussion of residential property). In a detailed study of residential properties, Hamilton et al (2016) found evidence to show that modelled energy savings calculated from deign-based models were rarely achieved in operation. They concluded that using modelled estimates of energy demand based upon design-based metrics such as EPCs will inevitably fail to be representative of actual demand and therefore savings. For instance, in the UK, (albeit without controls of intensity of occupation, use etc.) a study by Jones Lang Lasalle found that EPC B rated office buildings consumed more energy per square metre than E rated buildings (JLL, 2012). Van Dronkelaar et al (2016) found from 62 case study buildings, the average discrepancy between predicted and measured energy use was $+34 \%$. In their literature review, the most important underlying causes identified were building modelling specification uncertainty, occupier behaviour and poor practice in operation. This may help to explain the "operating expense puzzle" in Energy Star buildings in the US. The most recent study has found that energy consumption in Energy Star rated offices tends to be higher than non-Energy Star buildings (see Devine and Kok, 2015). 
A further potential source of policy failure is direct rebound and 'prebound' effects. Upgrades in energy efficiency for the lowest rated buildings may result in improvements in variables such as thermal comfort rather than by reduced energy consumption. Essentially, enhancement to a building's services (e.g. more energy efficient lighting and heating, ventilation and air conditioning) and fabric (e.g. increased insulation) that could reduce energy costs may improve both the building and increase the user's energy consumption (higher average temperature or more lighting) in the asset. The 'prebound' effect reflects a common phenomenon whereby low energy efficient buildings typically consume less energy than expected (according to a design-based model) (see Sunikka-Blank and Galvin, 2012). As energy efficiency improvements cannot save energy that is not being consumed, there are implications for the economic and energy efficiency of policy measures that then require upgrades to the building fabric and or the building's services. Consequently, due to rebound and 'prebound' effects, the introduction of minimum performance standards may not necessarily result in expected reductions in energy consumption and carbon emissions. This issue further reinforces the point that, for a policy instrument to be effective in reducing energy consumption (rather than simply improving the building stock), it should target actual energy consumption rather than hypothetical consumption. More fundamentally, this analysis suggests that there is a non-trivial possibility that upgrading buildings to improve their energy efficiency could result in increased rather than decreased energy consumption.

To date, other than England and Wales there are only two cases of countries that have introduced or plan to introduce MEPS for existing buildings. Scotland was actually the first country to introduce MEES for all non-domestic buildings over $1000 \mathrm{~m}^{2}$ in its Climate Change Act 2009 (implemented on 1 September 2016). There are many notable differences with the policy regime in England and Wales. Sales as well as lettings trigger compliance and domestic property is excluded. The Scottish approach is also conspicuously different to the English and Welsh in that the minimum required standard is compliance with 2002 Scottish Building Standards. A further major difference is that there is an 'operational route' to achieve compliance. If a building is non-compliant, then owners can do one of three things 
- Carry out building works to make it compliant.

- Make an Action Plan setting out when they are going to do these buildings works.

- Provide a Display Energy Certificate

The apparent rationale for this approach seems to have been to give owners the chance to reduce energy consumption by changing the building's operations instead of or as well as changing the building physically. There was an appreciation by policy makers that improvement works may be costly for both owner and occupier if the trigger transaction (sale and new letting) is 'out-of-cycle'.

A preliminary examination of the Scottish EPC data for non-domestic units in 2016 suggests a marked difference from the approach in England and Wales in terms of the stock affected. EPC data for 6825 non-domestic units was obtained. Whether or not, the unit is compliant with the 2002 Scottish Building Regulations was recorded for 5,436 of these EPCs of which 4,323 (79.5\%) were recorded as noncompliant. In contrast, for England and Wales, approximately $20 \%$ of units are non-compliant. Of the 4,323 non-compliant units, 487 were over 1000 square metres. However, these large units accounted for approximately $60 \%$ of the total floorspace that was non-compliant. This suggests that the Scottish approach exempts a large majority of transactions whilst affecting most of the transacted floorspace. The effectiveness of the policy is currently being evaluated in Scotland.

In late 2016 the Netherlands announced the introduction of MEES for all of its commercial office stock by 1 January 2023. Similar to England, Wales and Scotland, a lengthy notice period (seven years) has been provided to building owners. However, there are notable policy divergences in terms of stock affected, compliance requirement, staging of implementation etc. In the Netherlands, a cliff-edge rather staged approach has been taken and from 2023 all office stock (in Scotland and England and Wales it is only stock involved in a specified transaction) is expected to achieve minimum EPC C. ${ }^{2}$ Compared to the England and Wales, a much large proportion of the office stock will be affected. At the same time of the MEES announcement in the Netherlands, Economich Instituut voor de Bouw (EIB) published a

\footnotetext{
${ }^{2}$ It is also worth noting that there are significant differences between EPC ratings within the European Union. To be clear, an EPC C rating in Netherlands is not equivalent to an EPC C rating in England and Wales.
} 
report in 2016 where it is estimated that almost 23\% of office space had an EPC label. Starting with this figure and using building age for label approximation, the report estimates that MEES will affect 52\% of the Dutch office space in the first stage or approximately 43 million $\mathrm{m}^{2}$. Additionally, Redept (2017) estimated that $41 \%$ of leasehold and $56 \%$ of freehold office properties were non-compliant. Another 18 million $\mathrm{m}^{2}$ of office space will be affected in the second MEES stage which requires minimum EPC A by 1 January 2030 (EIB, 2016).

Following the announcement in late 2016 that the Netherlands would implement minimum energy performance standards for existing buildings in the office sector in 2023, the policy trajectory in the rest of the European Union seems also to be in this direction. In 2018, the review of the Energy Performance of Buildings Directive suggested to Member States that

"To further support the necessary improvements in their national rental stock, Member States should consider introducing or continuing to apply requirements for a certain level of energy performance for rental properties, in accordance with the energy performance certificates...To meet the objectives of energy efficiency policy for buildings, the transparency of energy performance certificates should be improved by ensuring that all necessary parameters for calculations, both for certification and minimum energy performance requirements, are set out and applied consistently." (European Union, 2018, paragraphs nine and 20).

This suggests that there is likely to be increasing adoption of minimum energy performance standards for existing buildings across the European Union.

\subsection{The Introduction of MEES in England and Wales}

Problems with detailed policy design can produce further policy failures. In England and Wales, policy implementation has been characterised as a 'soft start'. In 2011, it was announced that from 1 April 2018 a minimum performance standard had to be achieved at the point of letting. Hence, until 2023 
only non-domestic properties involved in leasing transactions have to meet the minimum standard. Consequently, owner-occupied non-domestic assets are effectively excluded from the policy. For leased properties, the fact that it is the owner (rather than the occupier) who is typically responsible for policy compliance has been a source of problems. The inclusion of lease renewals as transactions triggering compliance has meant that, due to continuity of occupation, there may not be a 'natural' window for upgrading works and occupiers have resisted the costs of business disruption caused by any works required to achieve policy compliance. In practice, buildings are also significantly and commonly altered soon after the EPC rating has been performed. For premises that involve substantial fit-out e.g. retail premises, significant reductions in potential energy efficiency can occur soon after an EPC rating has been assessed. One investor (in case studies produced by the Better Building Partnership) identified one estate of 44 buildings all built at the same time and to the same specification where achieved ratings ranged from $\mathrm{C}$ to $\mathrm{G}$, depending on how the occupier had fitted them out ${ }^{3}$.

Another (probably unintended) policy impact of the announcement of the introduction of minimum standards has been to improve the quality of the EPCs. Again, case studies produced by The Better Building Partnership provided examples of owners that have made their assets policy compliant by commissioning new EPCs. Typically, this has involved inputting better quality data into the EPC modelling software and minimising the use of (often worst case) default values. There are also concerns about effective policy enforcement. In England and Wales, the main concern is lack of government capacity with no provision for informing Trading Standards Officers when non-compliant transactions have occurred. With relatively small penalties, unclear exemptions and little chance of being discovered, it is expected that compliance among smaller landlords (and tenants) will be an issue. The most recent evidence is that there has been no enforcement proceedings by local authorities in England and Wales. Tomusk (2019) found that, following a freedom of information (FOI) request to every local

\footnotetext{
${ }^{3}$ In conversation, a researcher who performed much of the policy impact analysis for Dutch government informed the authors that he believed that retail premises had been excluded from the policy in the Netherlands due to the complications created by the level of tenant modifications to premises.
} 
authority in England and Wales, no local authority had undertaken any enforcement proceedings or prosecuted anyone for non-compliance.

Despite the long lead-in period or 'soft start', the introduction of MEES in the England and Wales garnered considerable interest from market participants. In addition to the government's own impact assessment, the Green Construction Board (2014) and the Investment Property Forum (2017) commissioned substantive industry studies of the implications and costs of compliance with the new regulations. The government's Final Stage Impact Assessment for the Private Rented Sector Regulations published in 2015 provided a broad assessment of costs and benefits. Its cost-benefit analysis estimated that, for the period 2014-2065, the costs of introducing the regulations for nondomestic properties would be $£ 1,234$ million in 2013 prices and the benefits would amount to $£ 3,756$ million. A substantial majority of the monetised benefits (86\%) were attributable to energy savings and most of the costs $(71 \%)$ were attributable to direct installation expenses. It is notable that the policy was initially designed so that there should be no upfront costs and no net costs to landlords. However, problems with the Green Deal and other financial incentives to introduce energy efficient technologies have meant that upfront costs have been incurred by both owners and occupiers.

Industry commissioned research on the expected impact of MEES has tended to focus on the costs, risks and potential responses of real estate owners rather than possible economic and environmental benefits. Perhaps obviously, the financial costs are projected to be most significant when required works to comply with MEES are relatively expensive and cannot be recovered through increased capital and rental values and/or payments for the necessary works by occupiers. An important issue is the extent to which energy efficiency improvements can be performed 'in-cycle' as part of more extensive refurbishment required to obsolescence and depreciation or fitting out works. In-cycle building upgrades will often be linked to or triggered by lease events such lease expiry. In-cycle energy efficiency improvements may then take place as part of a bundle of in-cycle works which would have occurred whether or not MEES had been introduced. As noted above, a significant proportion of such energy efficiency improvements prior and subsequent to policy implementation would have occurred 
without a MEES policy. It is also possible that some energy efficiency improvements may be introduced 'out of cycle' in order to comply with forthcoming implementation of regulation.

In the academic literature, Janda, Bright and Patrick (2018) reported on the results of an interview survey with industry experts and participants including owners, occupiers, managers and advisors. The categorised investor strategies as falling into 'active', 'protective' and 'avoidant'. It is notable that, even for investors categorised as active, the main approach was to identify actions. Similar to Mulliner and Kirsten (2017), they focus on the effects of the new standards on lease terms and the implications for rights of access to carry out works, provisions in services charge clauses for cost recovery, potential impacts of tenants' alterations, rent review negotiations inter alia. Whilst the focus on detailed landlord and tenant issues illustrates the complex mechanisms in which specific policy is transmitted to operational management, there is little assessment of the implications for energy performance.

The exemptions available suggest that it is likely that concerns about 'stranded assets' are unlikely to be realised. Currently, the 'soft start' policy seems designed to ensure that landlords can continue to lease properties that do not comply. Properties can be exempted from the minimum standards if the required works do not meet 'the Golden Rule' (a seven year payback period on expenditure on improvements), leases are for less than six months or consent to carry out the premises from the tenant has been refused. Such exemptions should enable the types of marginal, low value property where the expected returns on building upgrades could be minimal to continue to be leased. There is an analogy here with the extension of permitted development rights in the planning system which allowed a change of use from office to residential without the need for planning permission. Many local authorities, particularly in London, presented evidence that this policy reduced the stock of office premises available to businesses (London Councils, 2015). The consequence of the reduction in supply is expected to be an increase in rents. In turn, this would be expected to affect business in terms of employment and output as firms re-locate or close. Whilst there is likely to be a negative effect of non-compliance on value in terms of liquidity and suitability as debt collateral, the degree of flexibility in the MEES policy is not likely to force owners to either improve or remove their asset. Owners can simply claim 
exemption. As a result, in the short term, it seems that there are unlikely to be adverse effects on the types of businesses and business districts with concentrations of marginal businesses in marginal assets.

Following the announcement in 2010-11 of the intention to introduce MEES in 2108, real estate owners had a lengthy period to prepare for the implementation of the policy instrument. However, in terms of policy credibility, as the withdrawal of the Code for Sustainable Homes in 2015 illustrated, policy implementation was not certain. Nevertheless, research by industry bodies such as the Investment Property Forum (2017) and the Green Construction Board (2014) highlighted the engagement of market participants with the policy. Institutional investors seem to have focussed on ensuring that in-cycle works before policy implementation produced policy compliant assets. Nonetheless, this initial policy process evaluation suggests that there are theory and implementation failures in the MEES policy design. Mainly due to rebound effects, there are good reasons to question whether MEPS based on design-based metrics such as EPCs will be effective policy instruments for reducing energy consumption. The issues with user alterations post-EPC rating, difficulties with ongoing tenant occupation, ease of exemption and expected problems with enforcement capacity suggest that there is likely to be a degree of implementation failure. The so-called "soft start" to policy implementation further highlights a fundamental contradiction at the heart of the policy. Having introduced the policy announcing that it should not involve direct costs, the government was clearly concerned to minimise regulatory costs for asset owners and other stakeholders. As a result, policy implementation will be staged with rather unambitious minimum standards and a lot of scope to claim exemption. It is not at all clear that such a 'soft start' policy implementation is consistent with generating substantial improvements in properties nevermind the concerns about potentially limited impacts on energy consumption outlined above. Below, we provide some preliminary empirical evidence on changes to EPC ratings of $\mathrm{F}$ and $\mathrm{G}$ offices in London in the period prior to policy implementation but post-policy announcement.

\section{Methodology and Data}


The aim of the research is to identify improvements to buildings and to their energy performance ratings caused by the proposed introduction of MEES in the office sector. In order to address this aim, the methodological approach involves quantitative data analysis. Patterns of changes in EPC ratings are analysed for a large sample of the English office stock. Clearly, a key methodological challenge is to robustly distinguish between building modifications due to owners' decisions to comply with proposed MEES regulation and building modifications linked to the typical life cycle of the building carried out in order to counteract depreciation. A data filtering procedure has been applied to separate the former from the latter.

The key steps of the data filtering procedure are illustrated in Figure 2. Data on EPCs for non-domestic buildings for England and Wales are publicly available from Ministry of Housing, Communities and Local Government (https://epc.opendatacommunities.org) for the period 1 January 2008 until 29 September 2016. This broadly coincides with the announcement of the introduction of MEES until implementation. In order to generate a manageable but adequate sample, the first step in the filtering procedure was to select a specific geographical area. Given its pre-eminence as an office location, the office sector in London was chosen in order to gain the benefits of a large population of buildings with an EPC rating whilst minimising the resources required to extract data for all 348 local authorities in England and Wales. The second step was to filter for duplicate entries in the database. At this decision node the filtering process follows two paths. The first path, the left hand-side in Figure 2, aims to identify the population of study for this research. After filtering for duplicates the subsequent step in this path filters for land use by discarding all non-office entries. The final step in this path filters for energy labels by discarding all MEES compliant units to yield a database of all office properties in London with energy labels F or G. The overall database of all MEES-affected units comprises of 5,500 entries across all 33 London boroughs. The information included in the database relates to energy labels, asset rating of these labels, inspection/assessment date, floor area, building environment, transaction type, heating type and presence of air conditioning, among others. Table 1 gives an overview of the descriptive statistics for these variables for the population of study as detailed above. It is important to 
Table 1: Variable summaries for all MEES-affected London office units ( $\mathrm{N}=5500)$

\begin{tabular}{|c|c|c|c|c|c|c|}
\hline Variable names & Min. & Max. & Category 1 & Category 2 & Category 3 & Category 4 \\
\hline \multicolumn{7}{|l|}{ Continuous } \\
\hline Floor Area & 4 & 95,192 & - & - & - & - \\
\hline Assessment Date & 01/01/2008 & $27 / 09 / 2016$ & - & - & - & - \\
\hline Asset Rating & 126 & 1,470 & - & - & - & - \\
\hline \multicolumn{7}{|l|}{ Categorical } \\
\hline Label & - & - & $38.4 \% \mathrm{~F}$ & $61.6 \% \mathrm{G}$ & - & - \\
\hline Heating Type & - & - & $56 \%$ electricity & $41.5 \%$ natural gas & $1.5 \%$ oil & $1 \%$ other* \\
\hline Building environment & - & - & $28 \%$ air conditioning & $\begin{array}{l}68 \% \text { natural } \\
\text { ventilation }\end{array}$ & $\begin{array}{l}3 \% \text { mechanical } \\
\text { ventilation }\end{array}$ & $1 \%$ unconditioned \\
\hline Air conditioning & - & - & $24 \%$ yes & $76 \%$ no & - & - \\
\hline Transaction type & - & - & $50 \%$ marketed sale** & $5 \%$ non-marketed sale & $45 \%$ to let & - \\
\hline
\end{tabular}


point out that in the population of study G-label units are twice as many as F-labels and that the size range of these units is from $4 \mathrm{~m}^{2}$ to over $95,000 \mathrm{~m}^{2}$.

The second data filtering path aims to generate the sample of interest to this study namely the office units that have improved as a response to MEES policy. Initially the process has focused on duplicate entries in the database. ${ }^{4}$ Following the identification of duplicate entries, the subsequent step in this filtering path has isolated those entries whose initial use is office. The next step was to identify all $\mathrm{F}$ and $G$ labelled units which had a change in their EPC rating. The following filtering steps excluded units which did not improve to a minimum E label and units that had changed use. The overall outcome was to exclude non-compliant offices that changed use and all compliant units. In order to exclude EPC changes that did not involve building modifications, we excluded multiple entries for the same unit where the time period between EPC lodgements was extremely short. Rather than being caused by a response to policy, it is likely that the changes in the EPC reflected problems with the initial assessment or a fresh assessment following tenant fit-out. In a further step, units that showed a large improvement in EPC rating where filtered out since it is likely that these changes (e.g. from F/G to $\mathrm{C} / \mathrm{B}$ ) were due to

\footnotetext{
${ }^{4}$ It is important to point out here that, for the purpose of the analysis, this path retains all duplicate entries including the ones based on first lodgement date that were used to determine the population of study.
} 
Figure 2: Data filtering flowchart

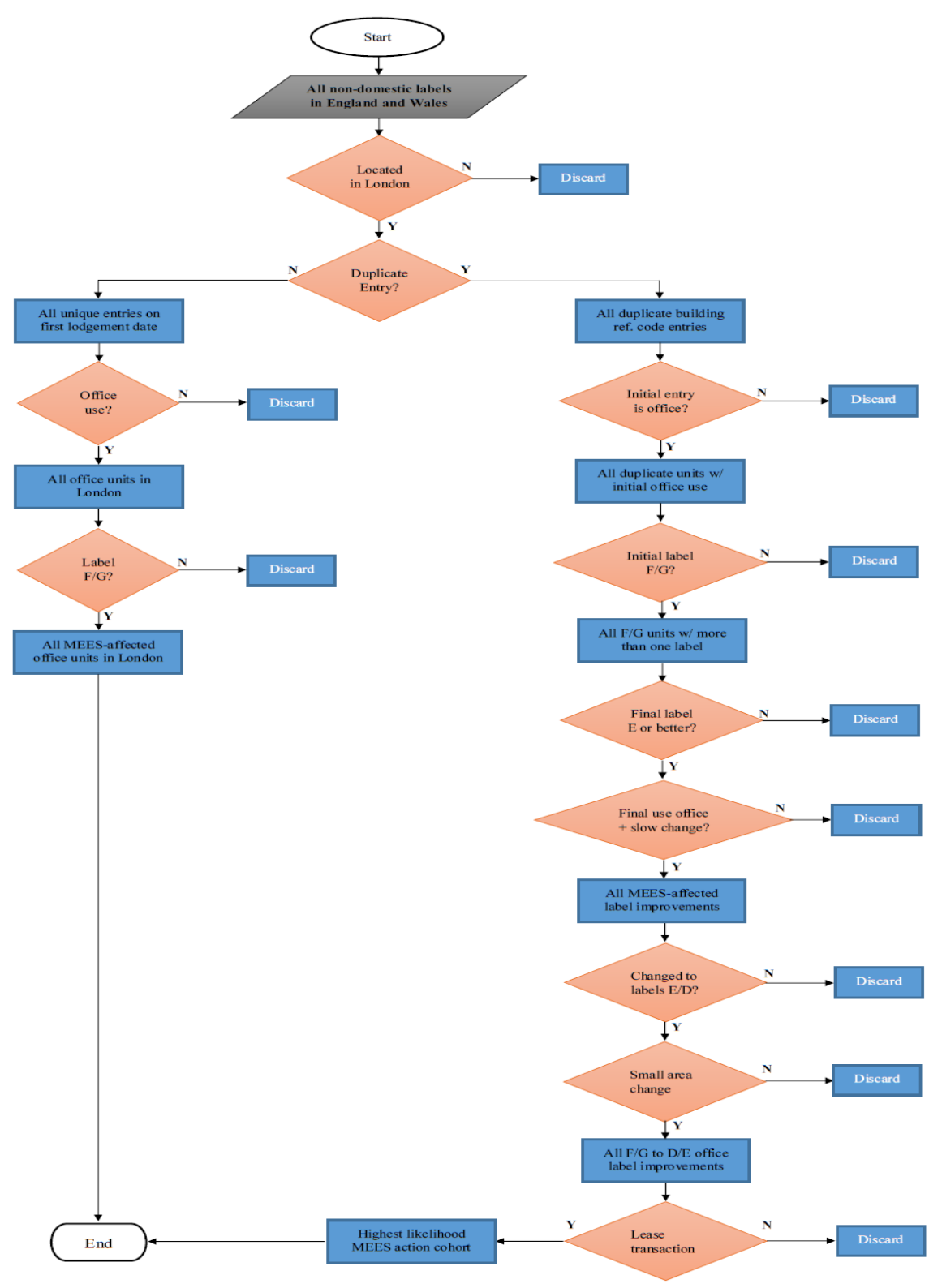


major in-cycle refurbishment works rather than works to achieve MEES compliance. The penultimate filtering step excluded units where a change in EPC was associated with a significant change in unit size. The rationale for this filter is that such a change in unit size would be the result of substantive incycle works. Finally, since only lettings are affected by MEES, sales transactions were excluded.

\section{Results and Discussion}

The results of the first two steps of the data filtering by geographical location and duplicates for the 33 London boroughs yielded 22,392 entries classified as office of which 844 were duplicates producing 21,548 unique observations. The filtering path focusing on the population of study produced 5,500 entries in the London database which had $\mathrm{F}$ or $\mathrm{G}$ ratings. This represented $25.5 \%$ of all office units in London that had a non-compliant EPC. In the other path of the filtering procedure (Figure 2), in order to identify properties that had changed their EPC rating and may have responded to the policy instrument, duplicates with an office initial use were extracted. Subsequently, the labelling filter was applied whereby only units with initial EPC label F or G were retained. This produced 324 office unit observations (building reference numbers) where more than one EPC certificate was registered. 81 of these observations either changed but did not reach the minimum threshold, remained below minimum at the same rating or experienced a deterioration in EPC rating from F to $\mathrm{G}$ after a new assessment and were, therefore, excluded. A further 66 observations were excluded because they have changed use. Most of use change within the non-domestic data set has been to retail and leisure with some storage and non-residential health ${ }^{5}$.

In the next step of the filtering, another 40 entries were excluded because there was a relatively short period between the two EPC lodgement dates. In $13 \%$ of cases, the EPC changed within one day. We excluded properties where the difference between lodgement dates was less than three months. Three

\footnotetext{
${ }^{5}$ It is likely that a significant number of office properties would also have converted to residential use. These properties have not been identified in this study since they are contained in a different data set. It seems unlikely that the decision to change use would have been caused by the introduction of MEES.
} 
more entries had a label change either before or too close to the policy announcement date and were subsequently deleted. The remaining 134 observations corresponds to $2.4 \%$ of the 5,500 units below the minimum energy efficiency threshold.

Of the remaining 134 observations, 34 (25.4\%) improved their EPC rating from F/G to C (24) or B (10) going considerably beyond the minimum threshold. The remaining 100 observations $-1.8 \%$ of the total F/G office buildings in London - seem to be the most likely cases of potential policy triggered interventions. The majority of the rating improvements were from F/G to $D(64)$ with the remainder moving from $\mathrm{F} / \mathrm{G}$ to the minimum $\mathrm{E}$ threshold. However, it is worth noting that a proportion of these 100 changes will also incorporate in-cycle building modifications or improvements in the EPC assessment without any building works. Some obvious building modifications are identified through an analysis of the floor area change between two lodgements using both absolute and relative values. There are in total 16 entries with significant area change which we attribute to major building improvements hence excluded from potential policy compliance action. Of the remaining 84 cases, 48 were sale rather than letting transactions and, therefore, were not directly affected by MEES. The remaining 36 cases, which are roughly $0.65 \%$ of the affected properties in London, constitute the cohort with the highest likelihood of policy compliance action. An unknown proportion of these properties would also reflect only changes to the EPC rather than changes to the properties or changes to buildings that would have occurred in the absence of the policy intervention.

Further investigation into the distribution of these label improvements by borough shows that there are 19 boroughs with no label changes, six boroughs with only one label change and four boroughs with two label changes. The remaining four boroughs showed the highest label improvement activity. As expected, the highest proportion of this activity has happened in the major office centres of Westminster (8), Camden (6), Enfield (5) and Kensington and Chelsea (3). Figure 3 below shows the distribution of label changes by boroughs of London. 


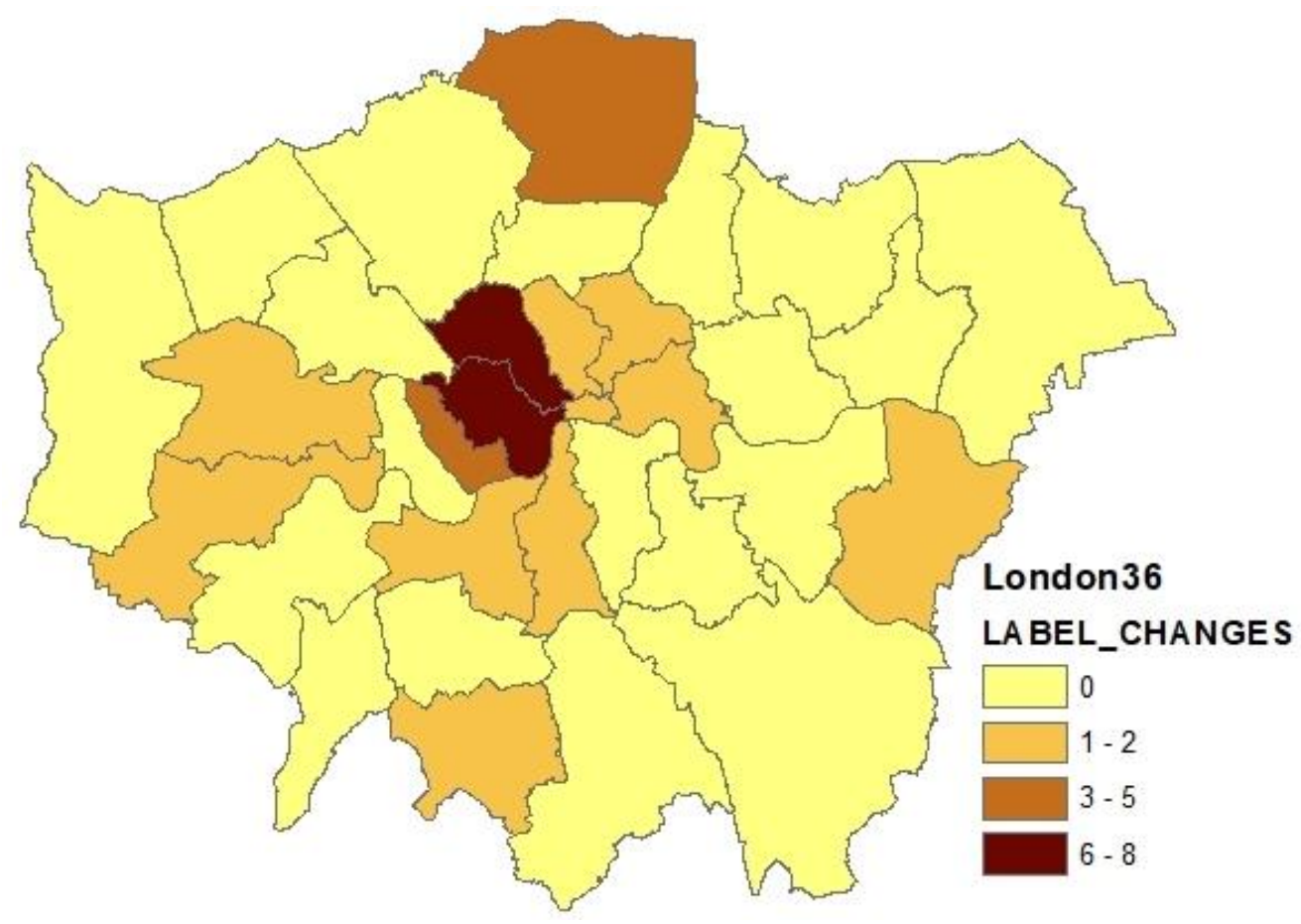

Figure 3: Distribution of EPC label changes across London

In order to better understand the profile of the highest likelihood MEES-compliant cohort and identify the segment with a proactive approach to this policy, a more detailed analysis is undertaken with the characteristics of the properties found in the database. These are namely floor area, transaction type, heating type, building environment type and for the case of the multiple building codes (improvements to higher labels) also the average time between two lodgement dates. The key figures are presented in Table 2. An important finding relates to the average property size which is almost double for the F/G to D/E improvements compared to all London office properties sampled. This has also been reflected in the overall square metres of the improved labels. More explicitly, while the proportion of office properties improved to labels D/E is $1.5 \%$ of all affected office units in London, this figure is double in terms of proportion of space (3\%). For the group of interest to this study, namely improvements to D/E labels in leasehold transactions, the same trend is observable albeit with a lowered impact. Average floor area in this grouping is approximately 50\% higher than the reference group described above and, while the 36 properties constitute $0.65 \%$ of the MEES-policy-affected offices in London their area is roughly $1 \%$ of the same benchmark. This would indicate that compliance action has in general been observed in larger properties. The fact that larger properties are associated with higher labels can also 
be observed from the size and numbers of all affected properties in London. While $25.5 \%$ of all offices are below the MEES threshold, this makes up just $17.4 \%$ of all office-classed space. Also the average size of properties changed to labels $\mathrm{B} / \mathrm{C}$ is over $23 \%$ higher than the average size of changes to labels $\mathrm{D} / \mathrm{E}$.

This finding indicates that larger assets (which are more likely to be owned by larger investors) can be expected to have a more pro-active attitude towards MEES policy. It would also indicate that policy improvements should focus on engaging the small-medium investors with relatively smaller assets. Coupled with the geographical distribution of policy related label changes, more concrete policy targets emerge with the focus of policy improvements being the off-prime assets of relatively small investors with a local profile. Considering the importance of centrality in the commercial sector property price gradients, this target profiling based on asset-investor-location interaction would be consistent across the major EU cities implying a wider policy impact. 
Table 2: Summary Statistics

\begin{tabular}{|c|c|c|c|c|c|c|c|}
\hline Office categories & Observations & $\begin{array}{l}\text { \# as \% of } \\
\text { nested sample }\end{array}$ & $\begin{array}{l}\text { Total floor } \\
\text { area }(\mathbf{m} 2)\end{array}$ & $\begin{array}{l}\text { Size as \% } \\
\text { of nested } \\
\text { sample }\end{array}$ & $\begin{array}{c}\text { Mean floor } \\
\text { area (m2/unit) }\end{array}$ & $\begin{array}{l}\text { Ave. time } \\
\text { between two } \\
\text { lodgements } \\
\text { (months) }\end{array}$ & $\begin{array}{l}\text { Transaction } \\
\text { type }\end{array}$ \\
\hline $\begin{array}{l}\text { All office } \\
\text { properties in } \\
\text { London with EPC }\end{array}$ & 21,547 & - & $20,546,000$ & - & 953 & - & - \\
\hline $\begin{array}{l}\text { All affected } \\
\text { properties (F\&G) }\end{array}$ & 5,500 & $\begin{array}{l}25.5 \% \text { of all } \\
\text { offices in } \\
\text { London }\end{array}$ & $3,575,874$ & $\begin{array}{l}17.4 \% \text { of all } \\
\text { offices in } \\
\text { London }\end{array}$ & 650 & - & - \\
\hline $\begin{array}{l}\text { More than one } \\
\text { label }\end{array}$ & 324 & $6 \%$ of $(F \& G)$ & 485,978 & $\begin{array}{l}13.6 \% \text { of all } \\
\text { affected } \\
\text { properties }\end{array}$ & 1,500 & - & - \\
\hline $\begin{array}{l}\text { All label } \\
\text { improvements }\end{array}$ & 134 & $2.4 \%$ of $(\mathrm{F} \& \mathrm{G})$ & 259,090 & $\begin{array}{l}7.25 \% \text { of all } \\
\text { affected } \\
\text { properties }\end{array}$ & 1,934 & - & - \\
\hline $\begin{array}{l}\text { Improvements to } \\
\text { B\&C }\end{array}$ & 34 & $0.6 \%$ of $(\mathrm{F} \& \mathrm{G})$ & 55,942 & $\begin{array}{l}1.6 \% \text { of all } \\
\text { affected } \\
\text { properties }\end{array}$ & 1,645 & 27 & $\begin{array}{l}59 \% \text { marketed } \\
\text { sale; } 35 \% \\
\text { lease; } 6 \% \text { non- } \\
\text { market sale }\end{array}$ \\
\hline $\begin{array}{l}\text { Improvements to } \\
\text { D\&E }\end{array}$ & 84 & $1.5 \%$ of $(\mathrm{F} \& \mathrm{G})$ & 112,029 & $\begin{array}{l}3.1 \% \text { of all } \\
\text { affected } \\
\text { properties }\end{array}$ & 1,334 & 26 & $\begin{array}{l}48 \% \text { marketed } \\
\text { sale; } 43 \% \\
\text { lease; } 9 \% \text { non- } \\
\text { market sale }\end{array}$ \\
\hline $\begin{array}{l}\text { Improvements to } \\
\text { D\&E (to let only) }\end{array}$ & 36 & $\begin{array}{l}0.65 \% \text { of } \\
(\mathrm{F} \& \mathrm{G})\end{array}$ & 32,558 & $\begin{array}{l}0.9 \% \text { of all } \\
\text { affected } \\
\text { properties }\end{array}$ & 904 & 22 & All lease \\
\hline
\end{tabular}


In the analysis of the changes to $\mathrm{B} / \mathrm{C}$ and $\mathrm{D} / \mathrm{E}$ labels we investigate differences for the other characteristics available in the database. By and large, there are no significant differences among the two categories with the average time between two lodgements being approximately two years. The grouping changing to D/E labels shows an equal distribution by heating type whereas the other grouping (changes to B/C labels) has a slightly higher proportion (56\%) of properties using natural gas for main heating purposes. Similar outcomes are also observed in the building environment category where slightly higher proportions of air conditioning are recorded for the changes to $\mathrm{B} / \mathrm{C}$ category. It is interesting to note that the proportion of air conditioning properties is relatively lower in the entries with the highest likelihood of policy compliance action. This might be related to the higher performance - lower energy usage - of buildings with natural ventilation compared to those with air conditioning.

\section{Conclusions and Policy Implications}

In the context of the real estate market, the introduction of MEES can be interpreted as a policy intervention to counteract apparent market failure and to remove the worst performing assets from the market. In England and Wales, the chosen policy instrument has been a minimum energy performance standard targeted at domestic and non-domestic rental properties. In terms of policy design, a secondary but key objective of policy makers seems to have been to minimise the costs of compliance to asset owners. There are trade-offs between the primary and secondary policy objectives. The introduction of MEES was announced eight years before implementation. Initially, it was intended that the direct costs associated with modifying buildings could be recovered by owners from subsidies. In addition, for the first five years, compliance is only triggered when a letting transaction occurs and rather undemanding exemption criteria are in place.

The fact that any actions by asset owners in response to MEES may persist from the point of policy announcement for a number of decades illustrates the challenges for ex post outcome evaluation. Nevertheless, there are strong a priori reasons to expect limited impacts of the policy in terms of reduced energy consumption. A key presumption underpinning the underlying theory of market 
transition is that improving the EPC rating of buildings will result in reductions in energy usage. However, there is evidence from the residential and commercial sectors consistently finding that good performance in design-based energy ratings is not strongly positively correlated with actual energy consumption. In particular, the evidence suggests that the "worst performing segments" consume substantially less energy than predicted in designed-based ratings. This non-trivial potential for perverse policy outcomes underlines the importance of robust policy evaluation.

Given that the MEES policy has been implemented relatively recently in England and Wales, at the time of writing outcome evaluation can only estimate policy impacts generated by the announcement of the policy and in anticipation of its implementation. It seems reasonable to infer that owners will take action to comply with policy in advance of its implementation only when it is optimal to carry out required work before a compliance triggering transaction. The findings on the post-announcement period indicate a low proportion of London office properties have taken policy compliance action. However, the findings suggest that the Department of Energy and Climate Change (2015) prediction that the estimate of $2 \%$ of total carbon savings between 2013-65 could be saved in the period 20132017 may be optimistic.

A notable outcome is that larger properties seem to have been affected by the introduction of MEES. This may reflect the interaction of owner and asset attributes. Institutional investors are more likely to own larger, higher value properties. This category of investor are more likely to have the asset management capacity, capital and corporate social responsibility policies enabling them to pre-empt MEES implementation. This too is consistent with anecdotal evidence suggesting that larger investors are more likely to comply with policy and take a pro-active approach to policy compliance. Multitenanted buildings, whilst they also tend to have more letting transactions, will also have fewer 'windows' for works to the whole building required for policy compliance.

In terms of policy outcomes, there are a number of significant challenges in policy evaluation. First, estimating the modifications to buildings that can be attributed to the introduction of MEES is likely to 
be resource intensive. As buildings are periodically improved in order to combat depreciation, robustly identifying building modifications that would not have been made in the absence of minimum standards requires details of the decision-making process for an adequate sample of properties. Second, the next challenge is to measure the effects of building modifications caused by the policy instrument on actual energy consumption and carbon emissions (as well as asset prices and/or space markets, productivity etc.). Given the complex range of determinants of these variables, obtaining data on the key confounding factors in order to isolate the impact of a specific policy-induced modification or modifications is a difficult issue. When a building is modified, it is possible that other changes will occur to the user, operating hours, equipment use, density of use etc. with the result that 'before-after' studies become prone to error. In particular, where there is evidence of potential rebound effects, it will be necessary to ensure that all alternative potential causal factors have been accounted for. Longitudinal cohort analysis seems to offer the most robust approach to evaluating policy instruments such as MEES which have been introduced in stages.

Whilst the focus of this paper has been of the introduction of the policy in England and Wales with a specific concentration on London offices, clearly the experiences of Scotland and Netherlands merit comparative evaluation from a policy learning perspective. Whilst there have been similar notice periods provided to owners, there are notable policy divergences in terms of stock affected, compliance requirements, staging of implementation, exemptions and enforcement. The experience of the three countries to introduce MEES so far illustrates the scope for different policy design. Given the policy trajectory suggested in the 2018 Energy Performance of Buildings Directive update, demand for evidence to support policy formation is likely to grow with a greater emphasis on outcome as well as process evaluation. 


\section{Bibliography}

Deloitte Real Estate. 2014. Carbon Penalties and Incentives. A review of policy effectiveness for carbon reduction and energy efficiency in the commercial buildings sector.

Department for Energy and Climate Change, 2015. Final Stage Impact Assessment for the Private Rented Sector Regulations.

Devine, A. and Kok, N., 2015. Green certification and building performance: Implications for tangibles and intangibles. Journal of Portfolio Management, 41, 151.

Economich Instituut voor de Bouw (2016) Verplicht energielabel voor kantoren, Can be downloaded at https://www.eib.nl/pdf/verplicht_energielabel_voor_\%20kantoren.pdf

European Union, 2018. Directive (EU) 2018/844 of the European Parliament and of the Council Green Construction Board, 2014. Mapping the Impacts of Minimum Energy Efficiency Standards for Commercial Real Estate, Final Report.

Hamilton, I.G., Summerfield, A.J., Shipworth, D., Steadman, J.P., Oreszczyn, T. and Lowe, R.J., 2016. Energy efficiency uptake and energy savings in English houses: A cohort study. Energy and Buildings, 118, 259-276.

Investment Property Forum, 2017. Costing Energy Efficiency Improvements in Existing Commercial Buildings.

Janda, K.B., Bright, S. and Patrick, J., 2018. Energy upgrades in commercial property: Minimum energy efficiency standards, compliance pathways, and leases in the UK. In Routledge Handbook of Sustainable Real Estate ( 37-54). Routledge.

Jones Lang Lasalle, 2012. A Tale of Two buildings. Are EPCs a true indicator of energy efficiency? Research Report. 
Mulliner, E. and Kirsten, L., 2017. Preparation for the Energy Act 2011 and minimum energy efficiency standards in UK commercial property. International Journal of Strategic Property Management, 21(2), 183-198.

London Councils. 2015. The Impact of Permitted Development Rights for Office to Residential Conversions, London Councils.

National Academy of Sciences, 2009. Real Prospects for Energy Efficiency in the United States: Consensus Study Report.

Redept, 2017. Consequences C-label already visible, Can be downloaded at https://redept.nl/app/uploads/2017/02/REDEPT UPDATE Consequences C label already visible.p $\underline{\mathrm{df}}$

Sachs, N.M., 2012. Can We Regulate Our Way to Energy Efficiency: Product Standards as Climate Policy. Vanderbilt Law Review, 65, p.1631.

Stavins, R.N., 2003. Experience with market-based environmental policy instruments. In Handbook of Environmental Economics (Vol. 1, pp. 355-435).

Sunikka-Blank, M. and Galvin, R., 2012. Introducing the prebound effect: the gap between performance and actual energy consumption. Building Research \& Information, 40(3), 260-273.

Tomusk, K. (2019) The MEES Landscape One Year On, Can be downloaded at https://www.egi.co.uk/news/mees-one-year-on-no-enforcement-proceedings-in-first-12-months/

Van Dronkelaar, C., Dowson, M., Burman, E., Spataru, C. and Mumovic, D., 2016. A review of the energy performance gap and its underlying causes in non-domestic buildings. Frontiers in Mechanical Engineering, 1, 17.

Van den Brom, P., Meijer, A. and Visscher, H., 2018. Performance gaps in energy consumption: household groups and building characteristics. Building Research \& Information, 46(1), pp.54-70. 